\title{
The Machinate Literary Animal: Butlerian Science for the
}

Twenty-first Century

\author{
Anna Neill \\ University of Kansas
}

\begin{abstract}
Current inquiry into nongenetic forms of inheritance has deep roots in the nineteenth century. Samuel Butler's evolutionary science writing and fiction points ahead, beyond the twentieth-century dismissal of pre-Darwinian science, to our own questions about how the experiences of an individual organism may effect change at the species level. This includes the way that symbolically mediated information, which rapidly shapes the human environment, exercises a downward pressure on slower-moving, genetic change. Butler's theories of unconscious memory and extended cognition, along with the Lamarckian principle that acquired traits could be passed on to descendants, together constituted an "evo-devo" approach to species history. In particular, language—specifically literary language-for Butler functioned as a machinate extension of the mind that could communicate transformative information to successive generations. Such extension therefore enables the little events of a lifetime to reach into the evolutionary future and transform it.
\end{abstract}

An early champion of Darwin who subsequently became a vocal critic of the theory of natural selection, Samuel Butler was at once part of the popular scientific community busy making sense of natural history in the wake of Darwin and a maverick outsider who "lost" in the evolution debates of subsequent decades. ${ }^{1}$ In his mature evo-

1. On Butler's relationship to the established and popular scientific communities, see Bernard Lightman, Victorian Popularizers of Science: Designing Nature for New Audiences (Chicago: University of Chicago Press, 2007), pp. 289-294, and “'A Conspiracy of One': Butler, Natural Theology, and Victorian Popularization," in Samuel Butler, Victorian 
lutionary writings, he looked back to Jean Baptiste Lamarck's concept of use inheritance, identifying with Herbert Spencer and others as part of "a growing band of those who have risen in resistance against the Charles Darwinian system" by protecting the theory of transmissible, acquired characteristics. ${ }^{2}$ Use inheritance, the development-centered theory that habits acquired during the lifetime of an organism could be passed down to its descendants (famously illustrated in the image of the giraffe stretching its neck for the higher leaves), was dismissed by twentieth-century biologists as a form of "just-so" story when Mendelian genetics supplied a mechanism for inheritance compatible with Darwinian selection. ${ }^{3}$ Neo-Lamarckism of the kind that Butler embraced, with its signature Victorian emphasis on self-improvement and progress, seemed at that point to be left in the dust heap of evolutionary-scientific history.

However, this ontogenetic (or developmental) emphasis in human evolution, including the principle that environmental changes could trigger heritable adaptations, did not vanish in the wake of the Darwin/Mendel, or modern, synthesis. In some ways, Butler's work is compatible with present inquiry into the nongenetic factors in evolution. The organism that will survive and reproduce, in the Darwinian model, is the one whose particular genetic configuration determines the phenotype providing the best fit for the environment, or "niche," it occupies. Yet, along with genetically inherited traits, environmentally triggered "switches" that determine whether or not a gene will be expressed, as well as learned behaviors that enable it to adapt to and transform its environment, also shape individual characteristics. ${ }^{4}$ Moreover, as they develop, organisms react to and reconfigure niches. ${ }^{5}$ Among humans, of course, culture plays

against the Grain: A Critical Overview, ed. James G. Paradis (Toronto: University of Toronto Press, 2007), pp. 113-142.

2. Samuel Butler, "The Deadlock in Darwinism," in Essays on Life, Art and Science, ed. R. A. Streatfield (London: A. C. Fifield, 1908), pp. 234-340, quote on p. 240.

3. Peter Bowler, The Eclipse of Darwinism (Baltimore: Johns Hopkins University Press, 1992), p. 60.

4. Recent studies of gene expression show that the DNA sequence does not necessarily have the executive function in development, and that nongenetic mechanisms may trigger heritable changes. See Eve Jablonka and Marion J. Lamb, Evolution in Four Dimensions: Genetic, Epigenetic, Behavioral, and Symbolic Variation in the History of Life (Cambridge, MA: MIT Press, 2005) and Epigenetic Inheritance and Evolution: The Lamarkian Dimension (Oxford: Oxford University Press, 1995); and Richard C. Francis, Epigenetics: The Ultimate Mystery of Inheritance (New York: W. W. Norton, 2011).

5. Eytan Avital and Eva Jablonka, Animal Traditions: Behavioral Inheritance in Evolution (Cambridge: Cambridge University Press, 2000), p. 311. 
an enormous role in this mutual constitution of environment and developing organism, and hence in shaping the biological landscape on which natural selection acts. As Peter Richerson and Robert Boyd put it, "[c]ulture . . . lead[s] to evolutionary processes that are every bit as real and important as those that shape genetic variation."

The study of late-nineteenth-century evolutionary science can contribute to such inquiry not just because it models the revival of use inheritance as a concept, but also because it introduces the factor of symbolic inheritance and its relationship to biological development and evolution. As both a popular science writer and author of fiction, Butler was predisposed to recognize narrative and print culture as factors in biological inheritance and species-level change. Writing preserved the events of a single lifespan and communicated these to future generations, where they then formed part of the environment of development. Yet, because he did not distinguish between physical traits and mental events, cultural inheritance was for him fundamentally a biological process. Proposing that life consisted in the automatically generated memories of ancestral forms or deep, unconscious "ideas," the mind became for him the locus of heredity, the place where every organism continually encounters its former incarnations. Written-down memories, because they outlast living brains, function as prosthetic tools that can expand our awareness of these earlier forms and the habits they have transmitted to us, where in the body these are only experienced as unconscious tendencies or reflexes. Writing that takes the form of literature, which deliberately manipulates perception and shows us our reflexes in an unfamiliar light, can, by this reckoning, shift innate ideas and thus directly alter the fortunes of species.

\section{Mind, Memory, and Extension}

Utopian as this all may sound, Butler's theories anticipate not only current investigation into the heritability of culturally acquired traits, but also an approach in contemporary cognitive science that does not limit thought and memory to what takes place in individual brains. A proponent of what is now called extended cognition, he understood mental activity as that which derives from external bodies as much as from internal nervous events, and that does not therefore respect firm boundaries between human and nonhuman, or between animate and nonanimate; thinking people, in this view, are fundamentally inseparable from the environments they encoun- 
ter, build, or manipulate. In many ways, Butler forecasted the wellknown thought experiment conducted by philosophers Andy Clark and David Chalmers in 1998, which asked whether the difference between an Alzheimer's patient who records directions in a notebook and a healthy person who stores this information in the brain might be only a matter of the degree of extension. ${ }^{7}$ Surely, Butler mused more than a century earlier, individuals cannot be discrete, bounded beings if we cannot draw a line "between the influence of those parasites which are within us but are not yet us, [or between] the external influence of other sentient beings and our fellow men?"8 Like Clark and Chambers, Richard Menary really only revives Butler's question when he challenges the readers of his recent Cognitive Integration to define the organic boundary between a spider and its web. ${ }^{9}$

For Butler, however, this dismembering of the bounded being takes place not just in the indeterminate space of extended cognition, but also across time. According to his theory of evolution, we belong as much to the remote past as we do to the present, and it is a deep, unconscious memory that links us to that past. In Life and Habit, he described all organic processes, physical and mental, as accumulated memories of ancestral behaviors that begin as acts of will, but that are routinized and then transmitted as habits into the traits of descendants. Life, in this understanding, is "knowledge [that has] passed through so many . . . as to become living and incarnate" (p. 40). As deliberate efforts of the conscious mind evolve into reflex activity (partly, in the interests of efficiency, in order that we do not have to keep remembering them), memory embeds itself below the threshold of awareness in "vast" and "infinite" (p. 50) repetitions that organize life at microscopic levels.

As I shall show later in this essay, Butler's fiction tried to animate these two axes of what might be called his extensionist evodevo: the development of the individual through its connection with other beings, as well as with the remote past. But the stories did not just reflect the philosophy; in fact, they provided an extension all of their own by lending imaginative form to the unthink-

7. Andy Clark and David Chalmers, "The Extended Mind," Analysis 58:1 (1998): 7-19. Republished in Clark, Supersizing the Mind: Embodiment, Action, and Cognitive Extension (Oxford: Oxford University Press, 2008), pp. 220-232.

8. Samuel Butler, Life and Habit (London: Trübner, 1878), p. 107. All subsequent page numbers in Butler's works are parenthetically cited within the text.

9. Richard Menary, Cognitive Integration: Mind and Cognition Unbounded (Basingstoke, UK: Palgrave Macmillan, 2007), p. 1. 
able-or specifically bringing to mind what is buried in the unconscious dimensions of organic experience. Although growth, in his terms, is a perpetual crossing into other entities and a remembering of earlier ones, we actually perceive nothing of this; indeed, in order to manage our day-to-day conditions of existence, we rely upon sense-bound convictions that biological entities and psychological personalities are bounded in time and discrete in form (p. 78). We are, nonetheless, willing to engage in cognitive play and to imagine the world outside of our habit-bound perspective: for example, Butler suggests, we can speculate that to a body infinitely larger than our own, all human-scale matter could appear a "lichen-like growth over the earth" (p. 129).

In itself, this exercise is clearly more literary than scientific. Butler's extravagant notion of extension-the idea that "we are rooted in outside things and melt away into them" (ibid.)—does not make, as he put it, "the smallest pretense to scientific value" (p. 1). Instead, its aim is to "entertain and instruct the numerous class of people who ... enjoy speculating and reflecting (not too deeply) on the phenomena around them" (p. 2). Indeed, for Butler, science itself has to become more like fiction if it is to open minds to this concept of development as a movement of other entities across and through us. At the same time, it must respect nature's constraints, even on imagination. All efforts to gather and advance knowledge, he stressed, must combine speculative thinking with deeply embodied ideas inherited from generations past. If treated like speculative writing, science can introduce ideas with "a painter's license" (p. 302) so as to shift some presuppositions—or, as Butler put it, "[think] to us" (p. 303). The scientist's "art" may, in this way, make us feel new things and act in new ways. Nonetheless, it must carefully assimilate these new ideas to old if we are to have any hope of absorbing them, for anything too foreign to our received understanding will wither and die. Only by respecting this economy of mind can science, fiction-like, "open a door," allowing us to glimpse "a strange and interesting transformation" (p. 306) or capture truths about our nature that escape the automatic thoughts shaping us from the past.

Butler's fiction-like science, therefore, hoped to generate new ways of being that could shift generations of habit. If, as he proposed, life consists of a vast collection of unconscious memories, then there must be a mechanism for evolutionary or phylogenetic change whereby older habits can eventually be supplanted by new ones. Were it the case that the circumstances of the past entirely shaped existence in the present, then there could be no real change in a species, merely an infinite building up of forms. Arguing that habits 
picked up by an organism during its lifetime could be transmitted to subsequent generations, Butler assumed that accidental discoveries or deliberate instruction could modify and improve an instinct. He proposed that such modifications, perhaps over generations, remain conscious until they stabilize into instincts and become part of the innate disposition of an organism. Yet, not all lower individuals will discover a route to more advanced nature in this way: "It would be enough that there should occasionally arise somewhat more gifted specimens of one or more original forms. These would vary and the ball would thus be set rolling, while the less gifted would remain in status quo provided they were sufficiently gifted to escape extinction" (p. 254). This notion of the "gifted specimen" allowed Butler to avoid both Lamarck's romance of inherent ingenuity in all life and Darwin's blind selection that denied all "motive power to originate and direct the variations which time is to accumulate" (p. 261). Evolution, he suggested, is driven neither entirely by deliberate striving nor by forces indifferent to the fate of species.

Alongside this theory that change depended on the appearance of the gifted specimen, however, was the problem of the excessive anomaly-the sudden appearance of a trait whose too-radical form meant it would not be able to accommodate itself to the world it inhabits. If a new element was too foreign to the environment in which the organism functions, he argued, if its "ideas" (or traits) were too radical and incapable of "fusion with preceding ideas" (p. 205), then it would fail to influence its descendants. This might be expressed in sterility, since all biological functions were ultimately "habits," an idea could potentially rupture reproductive potential or it might manifest psychologically in despair and thus probably in death. On the other hand, if the new form or gifted type were not too unfamiliar, it would "open the door for all manner of further variation-the new ideas having suggested new trains of thought, which a clever example of a clever race will be only too eager to pursue" (ibid.). This middle way allowed for variation and "crossings," yet also recognized the homeostatic constraints that sustain life across the generations.

The theory of heritable ideas and their variation implicitly asks whether those stored outside living bodies-the thoughts recorded in books and other nonbiological archives-are transmitted alongside or through organic memory. There are moments in Life and Habit when human cultural evolution seems to become a thing of its own, parallel or analogous, rather than entwined with biological change: 
The greater tendency of plants and animals to vary under domestication may be reasonably compared with the effects of culture and education: that is to say, may be referred to increased range and variety of experience or perceptions, which will either cause sterility, if they be too unfamiliar so as to be incapable of fusion with preceding ideas, and hence to bring memory to a sudden fault, or will open the door for all manner of further variation. (ibid.)

Like anomalous traits, new concepts may either come into the world stillborn, or they may generate cognitive variation from the deep script of heredity read over and over again by unconscious memory. Provided they do not overwhelm and destroy the individual entirely, such notions might interrupt the code of development and generate new habits that would, in turn, become part of the mental character of that individual and then of its descendants.

Therefore, it is the interweaving of inherited biological nature and inherited human culture-the way that culture is embedded in living bodies - that represents the truly development-centered nature of Butler's evolutionism. The key to this approach is to be found in associationist psychology. In his praise of Ewald Hering's 1870 lecture to the Imperial Academy of Sciences at Vienna "On Memory as a Universal Function of Organized Matter," Butler endorsed his colleague's associationist account of memory, thereby confirming both his own neo-Lamarckian conclusions that all the movements of living beings derives from an original volition that devolves over time into reflex activity, and also the principle that any such movement depends on interaction with the environment. For an associationist, molecular vibrations within the organism are alone too "feeble to generate action," which must be prompted by other, external objects. ${ }^{10}$ This is true even of memory, since recollection (or the reenactment of an action by habit) is triggered by the appearance of ideas that have themselves habitually produced such activity: "The action ensues which is proper to the vibrations of the particular substance under the particular conditions" (Unconscious Memory, p. 162). Therefore, as long as the relationship between external and internal vibrations remains relatively consistent, ideas will transmit more or less faithfully, but with some favorable variation, from one generation to the next. Of course, experience of the external world is neither consistent nor predictable. In Unconscious Memory, Butler devoted an entire chapter to a translation of Hering's speech, which argued that in human ontogeny, where infants develop less in vitro and more after birth than other, lower animals, there is a 
much more robust postnatal interaction between the body and the immediate environment. Humans develop "under the influence of impressions made by the environment upon [the] senses" and are thus more individualized than animals who receive their memories "readymade, and of a more final, stereotyped character" (p. 92).

Like Butler, however, Hering also stressed the limits to which radically foreign ideas can embed themselves in memory and thus achieve perpetuity through the medium of the body:

The most sublime ideas, though never so immortalized in speech or letters, are yet nothing for heads that are out of harmony with them; they must be not only heard, but reproduced; and both speech and writing would be in vain were there not an inheritance of inward and outward brain development, growing in correspondence with the inheritance of ideas that are handed down from age to age, and did not an enhanced capacity for their reproduction on the part of each succeeding generation accompany the thoughts that have been preserved in writing. (p. 94)

Ideas cannot be out of step with the brains that absorb and reproduce them-these are intertwined in evolutionary history; if ideas outstrip the minds they design to influence, they are rendered useless and sterile. The monstrous hybrids they attempt to incorporate into memory will bring about both their own demise and subsequently threaten the mental stability of the living beings on which they prey. At the same time, because "no organism can permanently outlive its experience of past lives" (p. 163), it will either die or else fall into a state of spiritual despair if it finds itself absorbing ideas that are too radical, foreign, or complex for its ancestral memories to accommodate. Yet, it is not only inherited predisposition, but "an enhanced capacity for their reproduction" that does allow new ideas to flourish. Here, Hering might be referring to increasing brain size; but equally, he might mean that certain human technologies, including writing, have opened the mind to a much greater range of possible ideas than it was formerly capable of absorbing, and subsequently recording and transmitting. By extending into the nonorganic environment, this would suggest, minds can entertain a much wider range of possibilities than biological memory dictates.

Writing, of course, exponentially enhances the reproduction of ideas. As David Amigoni has emphasized, Butler saw written symbolic communication consisting less of the material text-the "inkage and paperage" by means of which words are stored-as of the metaphors that enable ideas to move between minds and transpose ideas; they are therefore machinate extensions that enhance human 
communication. ${ }^{11}$ This very specifically literary conception of writing is also the means by which minds communicate ideas across time: "The written symbol extends infinitely as regards time and space, the range within which one mind can communicate with another. It gives the writer's mind a life limited by the duration of ink, paper, and readers, as against that of his flesh and blood body." ${ }^{12}$ The word becomes flesh in the transmission of ideas, but language's meaning vastly outlives the body it inhabits. Where literary language can extend the mind beyond that which it is biologically capable of entertaining, in other words, fantastic possibilities may live to become realities. Fiction, therefore, may entertain the outlandish without risking obscurity or cultivating despair; through its very form, it helps adapt readerly thought to a world larger and stranger than minds shaped solely by organic habit are capable of grasping.

\section{Machines of the Future in Erewhon}

Butler published Erewhon in 1872, followed by a revised edition in 1901, which included two new chapters representing much of what he outlined in Life and Habit. In the interim, he had temporarily stopped writing fiction to focus on his never particularly wellreceived accounts of evolution and development. On the face of it, the return to speculative literature did not seem any more promising, since such writing by its very nature trades in the impossible, positing radical visions of future or remote forms of life that leap too wide of the knowledge of the world lodged in our ancestral memory. Yet, the first edition of Erewhon had fared well, achieving, as Butler put it "unlooked-for success." ${ }^{13} \mathrm{~A}$ friend, he reports in the preface to the revised edition, attributed this success to the "sound of a new voice, and an unknown voice" (p. xiv). The qualities of "new" and "unknown" do not just refer to the fact that the story was published anonymously, but they also carry a charge in both its form and the content. As a satirical utopia in the vein of Swift's Gulliver's Travels, Erewhon deploys the rhetorical figure of defamiliarization. In so doing, it extends reading minds into forms of reflection they are not normally able to accommodate, even as it ties such unfamiliar ideas

11. David Amigoni, "Samuel Butler and the Writing of Evolutionary Theory," in Samuel Butler, Victorian against the Grain (above, n. 1), pp. 91-112, esp. p. 108; Samuel Butler, "Thought and Language," in Essays on Life, Art and Science (above, n. 2), pp. 176-233, esp. p. 195.

12. Butler, "Thought and Language" (above, n. 11), p. 198.

13. Samuel Butler, Erewhon, or Over the Range (New York: E. P. Dutton, 1927), p. xiii. 
to the unconscious memories that for Butler are fundamental to all life. It therefore tries to navigate a balance between the common sense of inherited ideas that every organism depends on to survive, and an "uncommon sense" that, with the help of wild literary imagination, can extend awareness into foreign and future landscapes, where it may shift even the most powerful cultural paradigms.

At the most obvious level, Erewhon makes the institutional pillars of Victorian society-education, finance, religion, and criminal justice-appear ludicrous, biased, hypocritical, and unfair under the traveler's gaze and in the unlikely setting of the New Zealand South Island alps. It turns out, however, that the story's antipathy is as much toward reformers who ignore the ingrained habits of ordinary people as toward the norms and prejudices of the Victorian social world. Erewhon depicts a society in which ideas are segregated from organic memory, with disastrous consequences. In particular, the three chapters on the Book of the Machines show how laws that violate evolutionary principles stunt human growth. Imported from articles Butler wrote for the new daily Christchurch publication The Press-"Darwin Among the Machines" (1863) and "Lucubration Ebria" (1865)-these chapters represent two different accounts of the posthuman future: the first is the horrific prospect of a world where machinate beings dominate humans; the second an optimistic forecast that the human incorporation of machines will expand our civilizational horizons. ${ }^{14}$ The Erewhonians, who have been encouraged by their intellectual leaders to adopt the first view, legislate against machines out of fear that they may extend mind so far that it will cast off the human body that nominally houses it.

Indeed, the political history of Erewhon has been, in large part, shaped by efforts to mute this evolutionary inevitability. Following a civil war between machinists and anti-machinists, the narrator learns, the country underwent a draconian political reformation. This break with history and tradition was founded on a single bookBook of the Machines - that prophesied mechanical inventions would usher in a new phase of mind as foreign to the present incarnation of consciousness as consciousness is to the most primitive incarnation of life. Recognizing that "everything is interwoven with everything" (p. 234), the book warned that machines develop infinitely more rapidly than animals, and anticipated a time when they could feel, think, and communicate independently and therefore dispense

14. Bruce Mazlish, "Butler's Brainstorm," in Prefiguring Cyberculture: An Intellectual History, ed. Darren Tofots, Annemarie Jonson, and Alessio Cavallaro (Cambridge, MA: MIT Press, 2004), pp. 228-239. 
entirely with the agency of human senses. In this future mechanical life, human beings, already the bondsmen of machines, would become merely parasitical on them or else enslaved, like the inferior species of dogs and horses are to humans. The author of this book shrinks with horror simultaneously at the idea that the human race could be surpassed in this way, and at the evidence to which it implicitly points of our primitive, nonhuman ancestry. Persuaded that they must do everything they can to prevent the monstrous eventuality of the posthuman future, therefore, the Erewhonians destroyed all their machines or else quarantined them in museums, and those suspected of using them were imprisoned or executed.

Even in their determination to avert this looming catastrophe, it must be said, the anti-machinists also recognized the power of technology to advance knowledge beyond anything that mere flesh alone is capable of discovering: the telescope, or "seeing engine" (p. 241), Book of the Machines conceded, has not only brought the "scenery of the moon" and the "geography of the planets" to the human retina, but in so doing, has appended itself to the very identity of the modern observing self. This is not a sudden and radical change in human experience, the author goes on to say, since an eye is really itself a machine the creature looks through, and the eye of a dead animal works for a time nearly as well as that of a living one. To tear the body away from the machines into which it extends, even this reactionary text admits, would be to render it senseless.

Although Erewhonian puritanism ultimately triumphed, the narrator discovers further evidence of an opposing machinist philosophy that, like the concessions made in Book of the Machines, emphasizes the marvels of extension. In this heretical text, machines are described as "extra-corporeal limbs" (p. 267): while lower animals keep their limbs attached to their bodies, its author points out, human beings have the advantage that they can distribute theirs across external space. Even as they undo the metaphysical coherence of human nature, such inventions add to "the resources of the human body" (p. 268). ${ }^{15}$ A man who digs with a spade has "modified himself not as other animals are modified, by circumstances over which they have had not even the appearance of control, but having, as it were, taken forethought and added a cubit to his stature" (ibid.). A man's memory, like the subject of Clark and Chambers's experiment, "goes in his pocket book," an "extra-corporeal member" (p. 269) that is more important to him than his hair or his whiskers.

15. Sue Zemka, "Erewhon and the End of Utopian Humanism," ELH 69:2 (2002): 439472, esp. p. 469. 
Such capacity for extension is the origin of civilization, sociality, and "all those habits of mind which most elevate man above the lower animals" (p. 268).

Of course, it is impossible to say that Butler's tongue was not somewhere in his cheek at this point. ${ }^{16}$ The machinist author seems to fall into habits of Erewhonian bigotry when he concedes that machines may "lessen the severity of competition" and thus trigger "a degeneracy of the human race" (pp. 268-269). He scarcely seems bothered that the incorporate body-the body that carries extra, artificial limbs-will be owned only by the most opulent citizenry, whereas the "souls of the poor [will remain] clogged and hampered by matter" (p. 270). The moral and intellectual improvement of mankind, which he holds up as evidence of the marvelous integration of organic and machinate entities, turns out to produce a natural deference of the poor toward the rich, like the "respect which all living creatures pay to those whom they recognize as higher than themselves in the scale of animal life" (p. 271). At the same time, the anti-machinist author of Book of the Machines continues to sound periodically like his opponent, challenging readers to identify a true distinction between human and machine: if we try to say that only the former exercises free will, or imaginative independence, we ignore the evolutionary fact that all life is constituted out of the agencies and forces that preexist it. Moreover, there is little that human beings can do to challenge their destiny: "A little reflection will teach us that the most daring flight of the imagination or the most subtle exercise of the reason is as much the thing that must arise, and the only thing that can by any possibility arise, at the moment of its arising, as the falling of a dead leaf when the wind shakes it from the tree" (p. 257). The absolute determinism of the anti-machinist sits uncomfortably with the will of his disciples to wipe out both the past and the future through the destruction of the machines; meanwhile, the natural hierarchism and degenerationist theories of the machinist undermine his veneration of the evolutionary advances that humankind has been able to make through its incorporation of machinate objects. Neither position, therefore, quite anchors the satire. Instead, Butler seems to hold up common sense, the collective body of memory that structures all life, as the truth in whose light every grand project and philosophical posture appear patently absurd.

16. See, for instance, Simon Dentith, "Imagination and Inversion in NineteenthCentury Utopian Writing," in Anticipations: Essays on Early Science Fiction and Its Precursors, ed. David Seed (Syracuse, NY: Syracuse University Press, 1995), pp. 137-152. 
Yet, because common sense, which ensures the continuity of the present with the past and patterns the future, is shaped by unconscious memory, it can only be brought to attention through the agency of an unfamiliar idea, and in the process becomes something else entirely. Were we to know the past and present fully and consciously, the machinist dreams, "the future, in its minutest details, would lie spread out before our eyes, and we should lose our sense of time present by reason of the clearness with which we should see the past and the future; perhaps we should not be even able to distinguish time at all; but that is foreign" (p. 258). Gifted with such lucid perception, humans would act toward every aspect of the present with the utmost care and proceed on the ground of utmost faith. As long as we believe that the future is a lottery, on the other hand, we will not truly work, but only speculate, and holding little more than a tremulous faith, we will inevitably drift away from moral principles. Satiric defamiliarization-the uncanny estrangement and distortion of the everyday that thrusts the reader into a remote and often topsy-turvy, yet oddly recognizable world-tries to open the present into the future by making that which is deeply familiar and therefore invisible, strange and therefore visible. It extends awareness into the unconsciously known past and present. And because it can be accommodated to common experience and inherited ideas, it leads neither to extinction nor despair. ${ }^{17}$

The possibility that satire itself may be part of the cure for Erewhon's political madness becomes quite overt in the closing chapters. "I can see no hope for the Erewhonians," the narrator remarks of their cruel or absurd laws, observing that "reason uncorrected by instinct is as bad as instinct uncorrected by reason" (p. 294). In this obvious allusion to the miserable alternatives of Swift's Yahoos and Hounynyms, Butler suggests that societies ignore the evolutionary past, and the common sense that embodies it in the present, at their peril. In a society that has wandered too far from common sense to be sustainable, the inhabitants "cut their [own] throats" (p. 272). Yet, irony itself may help them avoid their fate. Sections added in the revised edition on "The Rights of Animals" and "The Rights of Vegetables" introduce a prophet who wants to "reduce rights and wrongs to rules" and "put all sorts of matters on a logical basis," and who inspires legislation against eating meat. In the second added

17. Amigoni argues that satiric defamiliarization challenges the received accounts of human and European sovereignty that govern colonial and anthropological discourse; see David Amigoni, Colonies, Cults and Evolution: Literature, Science and Culture in Nineteenth-Century Writing (Cambridge: Cambridge University Press, 2007), pp. 142-163. 
chapter, he is answered by an Erewhonian philosopher, who speaks almost verbatim from Life and Habit, pointing out that since all life is a continuation of the personalities of its ancestors and that plants, like animals, are motivated only by the unconscious knowledge that forms them, there is no better reason to eat vegetables than animals. The satire moves in the opposite direction to something like Swift's A Modest Proposal, yet, it rests on a similar vision of cataclysm: the logic of care taken to extreme will starve the Erewhonians out of existence, whereas in Swift's Ireland the inhabitants are reduced to cannibalism. Presented with the absurd violation of common sense that their legislation entails, the Erewhonians repeal the acts forbidding the use of meat.

However, even as satiric defamiliarization speaks for common sense, it also becomes a tool of self-awareness, making us conscious of our bonds to the past and in so doing opening perception up beyond habit. Eating does become cannibalism when the comfortable, commonplace distinctions among human, animal, and vegetable are unsettled. Even though we "cannot get rid of persecution" because it is in the very nature of life-one entity is always assimilating another-we can become conscious of our relationships with other beings with the help of disquieting observations, such as "man is the only animal that can remain on friendly terms with the victims he intends to eat until he eats them." ${ }^{18}$ Where dogmatic reason and draconian reform merely crush and distort our self-knowledge and thus our true capacity for change, satiric irony-a device for making conscious what is unconscious-can open our eyes to our own nature, as well as to our profound connections with other living organisms.

Butler's use of utopian satire, with its blending of the foreign and the familiar, then, aims at nothing less than restructuring organic memory. This carries the risk, of course, that it will overextend and perish; and indeed, in its outlandishness, Erewhon seems to come perilously close to the kind of anomaly that is inevitably shortlived. The preposterous account of a society secluded in the New Zealand South Island alps, with its slippery satiric commentary on Victorian England, seems to flaunt this anomalous and incoherent character. Yet, Erewhon itself is the descendent of older satiric travel narratives, in particular Thomas More's Utopia, as well as Gulliver's Travels. Erewhon remembers a "nowhere" like More's-a utopia that offers a fantastic alternative to the exigencies of real political life-

18. Samuel Butler, The Note-Books of Samuel Butler, ed. Henry Festing Jones (London: A. C. Fifield, 1913), p. 82. 
and Gulliver's Hounynymland, the "discovery" of a deluded traveler where, for his at once culturally primitive, highly rational, and brutal and narrow-minded hosts, everything that Gulliver knows, wears, or carries represents a form of dangerous extension beyond the limits of the natural body. Like these earlier stories, it does not measure folly and vice against a norm of reason and virtue, but exposes the short-sightedness of both host and visitor in what one critic has called an "endless reversal of meanings." 19 Butler's ironic assertion in the preface that the truth of his story can be ascertained by its internal consistency therefore only points to an unacknowledged debt to earlier forms. His narrator, like most tall tale-telling travelers, breaks with the past by announcing at the very beginning that he will say nothing of his antecedents or the circumstances that led him to leave his native country. Thus, even as he claims his individual past is a blank, he invokes a common trope of entrepreneurial travel literature in which the events of early life are rushed over if not omitted altogether. Just as every action is linked to the ancestral past in human behavior, every gesture is motivated by apparently unconscious literary memory in narrative form, and brought to light through irony.

Ostensibly unaware of such literary debts, Butler described himself as the "enfant terrible of literature and science." ${ }^{20}$ His precocity, combined with his unconventionality, boasted a capacity to unleash thought from ancestral habits, outstripping those everyday endeavors by which we find "we have grown all our limbs on the strength of the likings of our ancestors and adopt these without question." 21 He claims for himself the genius described in Life and Habit of the "creature with exceptional powers of memory or reflection," who occasionally makes an appearance in "this race or that" (p. 245). Yet, Erewhon remains one of the two most well-read of Butler's works, confirming that even genius, at least if it is to be remembered as such, has ties to common understanding: it belongs to the world of the flesh. As "uncommon sense," genius is a "breach of the peace" that "points to a change and change is a hankering after another world";22 it lures us to another reality, "a state of things which has no counterpart here." Yet, it does not eradicate the past, but only

19. E. P. LeMire, "Irony in Erewhon," Humanities Association Bulletin 16:2 (1965): 27-36, quote on p. 27.

20. Butler, The Note-Books (above, n. 18), p. 183.

21. Ibid., p. 207.

22. Ibid., p. 175. 
"warps the woof of actions and things from the atom to the universe." ${ }^{23}$ The weaving metaphor is suggestive, evoking both the underlying architecture on which new structures can be built and the creation of new forms in the process of threading one fiber through another. Imaginative literature, even as it is embedded in the lifeworld, allows the mind to leap part way out of inherited disposition. Although it may represent what in other forms of life constitutes "too wide a cross," ${ }^{24}$ the utopian satire, the literary failure that Butler thought fell short of an "organic whole" (Erewhon, p. xvi) may alter the script of development; prompting outlandish and yet, at the same time, strangely familiar perceptions, it allows us to grow new limbs.

\section{Writing for the Future: The Way of All Flesh}

If utopian satire, for Butler, allowed strange twists of memory to challenge reason and political tyranny on the one hand and blind instinct on the other, the realist genre of Bildungsroman enabled him to navigate a path between patriarchal despotism and inherited disposition. Although he accused George Eliot of conservatism by comparing her success with the author who writes "fearlessly for posterity" and does not get paid for it, ${ }^{25}$ his posthumously published The Way of All Flesh followed most of the conventions of the Bildungsroman. Nonetheless, it looked ahead to the alienating forms and fractured selves of modernism, as it blended the story of individual development with Butler's theories of evolution and identity (and for that reason lived out his prediction that works of genius will achieve notoriety and impact only in future generations once they have been, to some degree, assimilated into perceptual habits). ${ }^{26}$ The trope of self-improvement that characterizes the Bildungsroman becomes in Butler's hands the "blending of unfamiliar elements" that, while it may produce marvelous innovations, may in subsequent generations result in unsuccessful or abnormal growths. ${ }^{27}$ Conversely, however, such corruptions of form may increase the physi-

23. Ibid., p. 176.

24. Samuel Butler, Luck, or Cunning, as the Main Means of Organic Modification? (London: Trübner, 1887), p. 32.

25. Butler, The Note-Books (above, n. 18), p. 160.

26. On Butler's proto-modernist play with realist form and the evolutionist conception of identity, see Sally Shuttleworth, "Evolutionary Psychology and The Way of All Flesh," in Samuel Butler, Victorian against the Grain (above, n. 1), pp. 143-169.

27. Samuel Butler, The Way of All Flesh (Harmondsworth, UK: Penguin Books, 1966), p. 25. 
cal and moral power of the anomalous structure-improvements "that might in some measure descend to [its] offspring" (p. 380). The uncertainties that attend such experimentation in The Way of All Flesh shape both character and plot.

The story traces the growth of the mind-in this case, the mind of Ernest Pontifex, the son of a minister, the grandson of a self-made man, and the great-grandson of a carpenter-not in a single life, but through multiple generations and in dynamic relationship with its surroundings. In so doing, it explores both how mind extends through time and how it is distributed across bodies. Thus, even while the novel shows personal identity determined by the evolutionary past, it also opens up the self to the chance encounters of the present, or the events that take place after birth, when the organism, faced with environmental influences, begins to forget some of what it knows at the cellular level about how to live ( $L H$, p. 60). The Bildungsroman, then, can record the emergence of traits that are only possible in ontogenetic time, while showing how these cut across deeply embedded tendencies from organic memory. With the help of " inkage and paperage," it can then allow the strange iterations of this process, including the unsuccessful ones, to be transmitted to future generations. Forms of life that would perish in the present may be recovered by future generations of readers, where they may be more successful and even eventually settle as habits.

Where the narrator of Erewhon learns nothing from his adventures and returns to England with the same narrow ambitions to wealth that fired his exploration of new territory, Ernest learns to overcome the self-punishing tendencies instilled in him by family and education to secure a more satisfying life and stable identity. The child of a frustrated clergyman who tries to bully his son into the life path and habits that his own father demanded of him, and an overly pious mother whose love for her children is outweighed by submission to her husband, Ernest's affections, desires, and inclinations (many of which are inherited from his much more decent paternal great-grandfather) bruise themselves against the authoritarian climate in which he grows, and he becomes incapable of reconciling his behavior with his sense of obligation. When, in early adulthood, his naïve confusion between desire and duty makes him the victim of a swindle, a failed clergyman, an unwitting seducer, and then a prisoner, he suffers a complete mental collapse, following which he is finally able to renounce his familial obligations and attempt to rebuild his life according to his own talents and wishes. A failed marriage, however, softens this determination to completely sever himself from his past, and, reconciled with his 
parents, he lives out the rest of his life as a writer who, in keeping with the barely concealed autobiography in this story, writes "queer, impractical" books, the most successful of which consist of essays that "steered between iconoclasm ... and credulity" (Way, p. 415), but that despite, or (in light of Erewhon) perhaps because of, its outlandish proposals "abounded with humour, just satire, and good sense" (p. 416).

During the period of his early youth when his psychological health is clearly in jeopardy, his godfather and caretaker Edward Overton (the narrator) expresses the hope that his godson's errors of judgment may be attributed to "postnatal rather than congenital misfortunes" (p. 289). Personality-shaping events that have occurred in the ancestral past, impressing the mind of the individual even before it is born, this suggests, deliver virtually inescapable consequences. The effects of accidents that occur in a single life, on the other hand, may be reversed, although it is also likely that they will create permanent effects that may be communicated to subsequent generations. Hence, the tragedy of the Pontifex line, where ambition has warped lives and minds by cramping innate behavioral tendencies too far. However, because in Butler's evolutionism ontogeny does not simply enact the script handed to it by phylogeny, the mind of the child does not unfold into maturity any more predictably than a young seal stays afloat "if put out of its depth before its parents have taught it to swim" or a young hawk can fly before it is taught (p. 333). Parental instruction should, by this logic, help the young animal to realize its potential. In human beings, this depends in large part on the prevailing cultural norms of childrearing or the attitude of "a sufficient number of reasonable people" (p. 53). In a culture that cultivates maxims like "spare the rod and spoil the child" and "check[s] the first signs of self-will," therefore, parents inevitably twist development away from its unconscious proclivities, with the result, as it threatens to be in Ernest's case, a steady slide toward despair.

The best hope for Ernest, it turns out, is a form of therapy that draws attention to our relationships with other beings. This treatment, sought out on his behalf by Overton, who assumes the role of parental caretaker, nurtures deliberately and consciously the kind of perpetual interchange between organisms and their environments that produces and sustains life: "All our lives long, every day and every hour, we are engaged in the process of accommodating our changed and unchanged selves to changed and unchanged surrounding, living, in fact, in nothing else than this process of accommodation" (p. 327). Ernest's suffering is directly caused by his 
efforts to suppress both the deep habits and the inherent otherness of mind, and by his conviction that failing to will himself into the person his parents wish him to be means (paradoxically) that he is "badly formed" (p. 203). Actively practicing accommodation of the external world, however, helps to heal the rift between familial indoctrination and inherited disposition. Too mentally exhausted even to be sent on a restorative European tour, he is instructed by a doctor to spend time at the zoo, examining the larger mammalsespecially the hippopotamus, rhinoceros, and elephants, who of all the animals offer the widest cross that Ernest can experience without taking the nervous risks associated with leaving his home country. "Seeing," the doctor proposes, "is a mode of touching, touching is a mode of feeding, feeding is a mode of assimilation, assimilation is a mode of recreation and reproduction, and this is crossing-shaking yourself into something else and something else into you" (p. 374). Despite a lingering suspicion that the doctor is not entirely serious, Overton embraces the strange possibilities in the satire and himself experiences these zoo visits as restorative, allowing "a new influx of life, or a new way of seeing life, which amounts to the same thing" (p. 375). By embracing the unfamiliar and willfully testing a new environment in which he encounters creatures remote from him in organic memory, he, like Ernest, changes his very emotional makeup. As a sort of psychotherapeutic dramatization of the theses of Life and Habit, the novel proposes that, although life is formed out of deep ancestral tendencies, seeing the fundamental interrelatedness of all matter enables transformations for the better in developmental time. Identity, Ernest's strange yet successful treatment reveals, is not discrete, for "we are infinite as regards time ... [and] extension" and "we cannot say where we either begin or end" ( $L H$, p. 104) ${ }^{28}$

Fostering the inter-species exchange of "ideas" in this way amounts to much the same thing in Butler's terms as using language. Language is the "intentional conveyance of ideas from one being to another through the instrumentality of arbitrary tokens or

28. Amigoni points out that this is a scene simultaneously of hybridization (crossing) and "parenting." It is perhaps for this reason that it provides a therapeutic alternative to the "trauma" of crossing (in the overthrowing of habit) that Danielle Nielsen identifies as a key evolutionary trope in The Way of All Flesh. See David Amigoni, "Charles Darwin's Centenary and the Politics and Poetics of Parenting: Inheritance, Variation, and the Aesthetic Legacy of Samuel Butler," in Evolution of Literature: Legacies of Darwin in European Cultures, ed. Nicholas Saul and James J. Simon (Rodopi: Amsterdam, 2011), pp. 73-85, esp. p. 84; and Neilsen, "Samuel Butler's Life and Habit and The Way of All Flesh: Traumatic Evolution," English Literature in Translation, 1880-1920 54:1 (2011): 79-100. 
symbols agreed upon." ${ }^{29}$ In his essay "Thought and Language," he argues that human beings are not, by virtue of language, specially created outside of the process of descent with modification. As long as language is understood as the transposition of ideas, the communication of ideas "to another living being," lower animals must be said to possess it also. All animals can "remember, reflect upon, modify these ideas according to modified surroundings, and interchange them with one another." As language, the crossing of ideas provides a horizontal axis of variation within the lifetime of an organism that cuts across the vertical transmission of ideas through descent.

Yet, if language in this broad sense is not unique to human beings, written language, which "leaves a material trace as long as paper and ink last," is most certainly so. The capacity of written words to leapfrog over time and speak their ideas to later generations renders those physical words-agreed-upon symbols that carry ideas from one mind to another-machinate extensions of the bodies that call and reach out to others. It is in this sense that anomalous works of "genius" may take hold and create a species-level turn in habit. Ernest's one literary success, a work titled Essays and Reviews, recalls Erewhon in its outlandish proposals about his society (including a eugenicist notion that the highest good depends on the greatest happiness of the beautiful and well-bred) and in the way it rings "alike with conviction and the lack of conviction" (p. 415). His talent, like Butler's own, is considered by most people to be of a "queer, impractical" kind (p. 429), and it always creates the impression that he speaks in jest. The uneasy feeling of being mocked that his contemporary readers and would-be publishers feel suggests that its genre is satire-in other words, that it estranges and brings to light something so profoundly habitual that it has escaped the notice of reasonable people. The instinctual revulsion of the flesh that Ernest's determination to offend creates and his willful refusal to "write like other people" (p. 428) withers his career as the writer in the present. But in a utopian vein, it aims to open the eyes of future readers-readers whose habits may have adjusted to its sensory assault thanks to the influence that inkage and paperage can achieve over time. Satiric writing will, in this way, cause a shaking up and out into other ways of being, or so Ernest presumably hopes when he replies to his frustrated publisher with only one word: "- 'wait'" (p. 430).

In a recent issue of The Chronicle of Higher Education, William Ger- 
mano challenged writers of scholarly books to exchange the "snow globe" approach to academic writing - a "perfect, tidy, improbable world where no questions are asked, or invited-for the "machine model." In machine writing, he suggested, the work waits to have something done with it rather than inspiring detached admiration: "the book-as-machine should trouble or excite . . . or even confuse." ${ }^{30}$ Butler-surely a writer who, rather than sealing off impossible, strange, or utopian worlds, maneuvers them to speak forward into our intellectual era-seems to answer this challenge. His novels suggest the work of literature in the evolving world and the possibility that, as Amigoni puts it, "books could become machinate extensions of the human." ${ }^{31}$ Embracing aberrations in both cognitive and cultural development, they offer to rupture unconscious memory in a way that promises species-level change; stories written for readers who cannot yet swallow them whole, they represent impossible breaks with the past. And yet, they are like cunningly wrought artificial limbs that may, in time, become attached to living human bodies.

30. William Germano, "Do We Dare Write for Readers?" The Chronicle Review, April 22, 2013. http://chronicle.com/article/Do-We-Dare-Write-for-Readers-/138581/.

31.Amigoni, "Samuel Butler and the Writing of Evolutionary Theory" (above, n. 11), p. 108. 